\title{
"ELES FICAM LOUCOS COM NÓS": AS LÓGICAS DE CORPO E GÊNERO EM ADOLESCENTES EXPLORADAS SEXUALMENTE
}

"THEY GO CRAZY ABOUT US": THE LOGIC OF BODY AND GENDER IN SEXUALLY EXPLOITED ADOLESCENTS "ELLOS SE VUELVEN LOCOS CON NOSOTRAS": LAS LÓGICAS DE CUERPO Y GÉNERO EN
ADOLESCENTES EXPLOTADAS SEXUALMENTE

Monise Serpa*

\begin{abstract}
RESUMO
Este estudo tem como objetivo analisar como as questôes de corpo e gênero foram vivenciadas por adolescentes do sexo feminino envolvidas com a exploração sexual nas suas experiências cotidianas. Analisaramse os processos de erotização do corpo infantojuvenil e os seus efeitos na constituição da feminilidade, assim como as lógicas de valorização e controle da sexualidade das adolescentes estudadas. Participaram três adolescentes do sexo feminino, envolvidas com a exploração sexual e com idades entre 13 e 17 anos. Foram empregadas atividades em grupo com materiais lúdicos e um roteiro de entrevista semiestruturado. Os resultados apontaram que a sensualidade e a virgindade apareceram como uma forma de afirmação da feminilidade das interlocutoras, tanto para o seu empoderamento como para sua vulnerabilidade perante a sociedade. Observa-se a importância de estratégias que permitam às adolescentes estabelecerem comportamentos mais autônomos na manifestação da sua sexualidade, pautados em uma lógica que as considere como sujeitos de direitos.
\end{abstract}

Palavras-chave: Exploração sexual. Corpo. Gênero.

\begin{abstract}
This study aims to analyze how female adolescents involved in sexual exploitation along their everyday life experienced body and gender issues. The erotization processes of children's and youths' bodies were analyzed in addition to its effects on the constitution of femininity and the valorization and control of the sexuality of the studied adolescents. Three female adolescents, aged from 13 up to 17 who had been involved in sexual exploitation took part in this study. Both, group activities with playing materials and a semi-structure interview were used. Results showed that sensuality and virginity turned out as a way towards the subjects' affirmation
\end{abstract}

\footnotetext{
Texto recebido em 20 de outubro de 2014 e aprovado para publicação em 11 de fevereiro de 2016.

* Doutora em Educação pela UFRGS, mestra em Psicologia pela Universidade Federal do Rio Grande do Sul (UFRGS), professora de Psicologia da UNF. E-mail: monise.serpa@gmail.com.
} 
of femininity either for their empowerment as well as for their vulnerability before the society. It is outstanding the importance of strategies which enable adolescents to develop autonomous behavior for the expression of their sexuality, based on a logic that considers them subjects of rights

Keywords: Sexual exploitation. Body. Gender.

\section{RESUMEN}

Este estudio busca analizar como las cuestiones de cuerpo y género fueron vividas por adolescentes de sexo femenino involucradas con la explotación sexual en sus experiencias cotidianas. Se analizan los procesos de erotización sexual del cuerpo infanto-juvenil y sus efectos en la construcción de la feminidad, así como las lógicas de valoración y control de la sexualidad de las adolescentes estudiadas. Participaron tres adolescentes de sexo femenino involucradas en exploración sexual, con edades entre 13 y 17 años. Fueron utilizados materiales lúdicos y un guion de entrevista semiestructuradas. Los resultados señalan que la sensualidad y la virginidad aparecen como una forma de afirmación de la feminidad de las interlocutoras, tanto para su empoderamiento como para su vulnerabilidad ante la sociedad. Se observa la importancia de estrategias que permitan que las adolescentes establezcan comportamientos más autónomos en la manifestación de su sexualidad, guiados por una lógica en la que se las considere sujetos de derechos.

Palabras clave: Explotación sexual. Cuerpo. Género.

\section{INTRODUÇÃO}

exploração sexual tem sido apontada como uma das maiores violações aos
direitos da criança e do adolescente, considerada uma forma moderna de
escravidão (Faleiros, 2004). E assim, tal realidade vem se colocando como prioridade nas ações dos governos no mundo todo, como mostraram os congressos mundiais realizados a partir da década de 1990. O primeiro deles ocorreu na cidade de Estocolmo, Suécia, em 1996; o segundo, em Yokohama, Japão, em 2001; e o terceiro, no Rio de Janeiro, Brasil, no ano de 2008 (Libório, 2004). No Brasil, a discussão sobre esse problema, incluído na categoria de violência sexual, também ocorreu na década de 1990, quando o fenômeno da exploração sexual passou a ser alvo de debates entre autoridades e pessoas ligadas à área da infância e da adolescência. Tal fato aconteceu principalmente a partir de denúncias suscitadas por instâncias governamentais, Organizações Não Governamentais (ONG) das regiôes Norte e Nordeste e por jornalistas. Um dos trabalhos mais conhecidos foi o do jornalista Gilberto Dimenstein, feito em 1992, no norte do País, resultando no livro Meninas da noite: a prostituição de meninas-escravas 
no Brasil. Em resposta a essa mobilização, o Congresso Nacional instaurou uma Comissão Parlamentar de Inquérito (CPI) da Prostituição, no intuito de apurar os responsáveis nas diversas regiōes do País (Santos, 2004; Libório, 2004). De acordo com Leal (1999), houve então um avanço na compreensão sobre tal realidade, especialmente com a mudança da terminologia "prostituição infantojuvenil", para "exploração sexual". Crianças e adolescentes, ao estarem nessa situação, não estão se prostituindo autonomamente, mas sendo "vitimizados" pela prática criminosa de adultos.

Conforme apontado no estudo realizado por Mello (2010) a respeito da produção científica no Brasil sobre a exploração sexual, não há uma definição precisa na conceituação sobre essa realidade por muitas vezes ser classificada como prostituição-infantil ou, como na maioria dos casos, abuso sexual. Essa mesma "confusão" conceitual é também retratada em pesquisas feitas com profissionais atuantes nos serviços de atendimento a crianças e adolescentes vítimas de violência, dificultando, muitas vezes, a realização da pesquisa sobre o tema (Serpa, 2009; Vega, 2011). Porém, segundo Landini (2011), há uma concordância, na maior parte dos trabalhos voltados para essa realidade, de que a prática sexual envolvendo uma criança ou adolescente e uma pessoa adulta é uma violação aos direitos humanos por ser estabelecida numa relação desigual de poder. De acordo com o que foi acordado no I Congresso Mundial sobre a Exploração Sexual de Crianças e Adolescentes, realizado em Estocolmo, em 1996, a exploração sexual é toda ação que envolve o corpo de crianças e adolescentes, seja do sexo feminino ou masculino, para a obtenção de vantagem ou proveito sexual, baseadas numa relação de poder e de exploração comercial (Leal, 1999). Apesar de considerar essa questão, Landini (2011) ressalta os limites, principalmente na realização de pesquisas, trazidos por essa definição por não deixar claro como crianças e adolescente, nas suas variadas formas, fazem uso do sexo por dinheiro. Colocá-los na condição de abusados ou explorados sem atentar para os diversos movimentos realizados por crianças e adolescentes nesse processo poderá engessá-los numa perspectiva homogeneizada, "sem vontade própria ou agência" (p. 61). Assim, os estudos realizados não somente por Landini (2011), mas por Serpa (2010b), Ennew (2008), Trindade (2005) e Moraes $(1998 ; 2011)$ apontam que o envolvimento com a exploração sexual pode ocorrer de diferentes formas, desde a fazer programas para adquirir objetos de consumo ou para estabelecer relacionamentos afetivos.

Dessa forma, faz-se necessário entender o contexto no qual essa prática se dá, os sentidos produzidos nas relações estabelecidas pelas pessoas envolvidas que, conforme discutido por Mello (2010), envolve questões tais como lógicas de mercado, abuso de poder do corpo de crianças e adolescentes por parte de 
"mercadores", pais ou responsáveis, consumidores, e por que não consumidoras, dos serviços sexuais. Nessa discussão, a dimensão do corpo passa a ser um elemento importante na análise da exploração sexual por ser um dispositivo concreto no qual se presentifica o ato da violência sexual. Analisar as dimensões físicas, psicológicas e sociais desse corpo se faz necessário para entender a relação que a adolescente estabelece com ele e com as demais pessoas envolvidas na situação de exploração sexual.

Este estudo parte da perspectiva dos estudos culturais e pós-estruturalista no qual entende o corpo como elemento que se constitui no social, está em permanente aprendizado nas relaçóes que estabelece, seja no contexto familiar, escolar, no trabalho, nas redes sociais virtuais, nos livros, bem como no contexto midiático (Andrade, 2013). Nessas relações, são ensinadas formas de o sujeito pensar, agir e sentir em relação a si e ao outro. Tal concepção, segundo Goellner (2013), rompe com a noção naturalista sobre o corpo ao demarcá-lo como histórico, e, por isso, transitório, modificável. O corpo também é cultural, é o seu "entorno", ou seja, aquilo que produzimos sobre ele, tais como roupas, acessórios, alterações cirúrgicas (plásticas) ou técnicas de modificação (“bodymodification”). O corpo também é linguagem, ou seja, é o que se diz sobre ele, os sentidos que passam a fazer parte dele num determinado momento histórico, numa determinada cultura. Nesse sentido, a autora segue afirmando que conceber o corpo dessa forma não é negar a sua "materialidade", ou seja, a sua dimensão biológica, mas é problematizar sua centralidade nas discussões e explicaçôes sobre os diferentes modos de ser e atuar no mundo (Goellner, 2013).

Segundo a autora, foi no fim do século XVIII e durante o XIX que o corpo ganhou importância nas interaçôes estabelecidas entre as pessoas, constituindo uma "moral das aparências", ou seja, o que mostramos passa a demarcar aquilo que de fato somos (Goellner, 2013). Para Goldenberg (2011), na nossa sociedade, o corpo almejado e produtor de desejo é um "corpo-moeda", que, ao mesmo tempo, é produto de compra e venda, um corpo investido de uma economia da sexualidade, gerando nas mulheres o desejo de investir no seu corpo, principalmente na sua aparência, por meio de tecnologias de embelezamento, tais como cirurgias plásticas, exercícios físicos e cosméticos. Atualmente, o corpo almejado é o exercitado, jovem, produtivo, belo e, por isso, o obeso, flácido, sinaliza um descuido de si, falta de vontade ou controle, algo a ser combatido cotidianamente (Goellner, 2013; Meyer \& Soares, 2008). Nessa perspectiva, cabe refletir o contexto do mercado do sexo e como esse "corpo-moeda" transita na prática da exploração sexual de adolescentes do sexo feminino.

A erotização dos corpos femininos vem sendo mostrada nos meios de comunicação, como tevê, internet, revistas, jornais, assim como suas 
propagandas, nos quais é possível constatar novas formas de "exploração dos corpos e da sexualidade" (Felipe, 2013, p. 56). A inclusão de crianças e adolescentes nessa realidade aconteceu por ser uma "mercadoria" de extremo valor comercial. Para Leal (1999), o corpo infantojuvenil é um produto do mercado globalizado do sexo que utiliza o marketing e a publicidade para divulgar uma lógica de hipererotização do corpo feminino, fortalecendo perspectivas de submissão e desqualificação da mulher. Para Felipe (2006), essas concepções vão produzir efeitos significativos na forma como crianças e adolescentes vão conceber seu corpo e sua sexualidade. Assim, faz-se necessário problematizar a questão da exploração sexual também com base nas questões de gênero, pois estas criam modos ser homem e mulher, numa determinada sociedade, numa determinada cultura e momento histórico. $\mathrm{O}$ conceito de gênero, originado das teorias feministas anglo-saxãs, busca dimensionar as discussões sobre o ser homem e mulher no processo social e cultural, afastando-se dos essencialismos biológicos (Louro, 2013). Dessa forma, segundo a autora, as explicações para as desigualdades estabelecidas entre homens e mulheres não estariam nas diferenças biológicas, mas nas relações sociais, no processo histórico, na acessibilidade aos recursos disponíveis na sociedade em questão. Em nossa sociedade, são definidas características específicas para cada gênero, o que dará a cada um dos sujeitos um lugar social, um espaço de pertencimento a um determinado grupo, formando assim sua identidade de gênero. A escola, a família e as pedagogias culturais teriam esse papel constante de afirmar, constituir, controlar essas identidades de gênero a partir daquelas consideradas referência naquela cultura, naquele grupo social (Guizzo \& Felipe, 2003). Assim, este estudo pretende analisar como as questôes de corpo e gênero foram vivenciadas por adolescentes do sexo feminino envolvidas com a exploração sexual nas suas experiências cotidianas. Nessas experiências serão abordados os processos de erotização de seu corpo, a partir do forte investimento afetivo, sexual e financeiro feito por parte dos homens, como exercício de sua masculinidade heterossexual. Por outro lado, esse corpo também será retratado com alvo de controle da sexualidade feminina que tem nas concepções sobre virgindade um dos seus maiores ícones.

\section{MÉTODO}

\subsection{Delineamento}

Devido às características específicas do objeto de estudo e pela necessidade de aproximação da pesquisadora às interlocutoras no contexto institucional, utilizou-se o método de inserção ecológica. Esse método de pesquisa favoreceu o desenvolvimento da empatia e da confiança entre a pesquisadora e as participantes 
(Eschiletti, Paula, Moura, Poletto, \& Koller, 2008). Segundo as autoras, tal método consiste em analisar os processos de interação entre as pessoas e o contexto no qual estão inseridas, sendo o ambiente um aspecto fundamental de investigação, já que nele ocorrem os processos de interação. Utilizou-se também do estudo de casos múltiplos, método que permitiu uma análise mais abrangente dos dados obtidos na pesquisa (Yin, 2001).

\subsection{Contextualização do local}

A pesquisa foi realizada em uma instituição filantrópica voltada para o atendimento de crianças e adolescentes em situação de risco e vulnerabilidade social. A instituição era mantida e gerenciada por uma entidade religiosa que mantinha parceria com a Prefeitura Municipal de Porto Alegre ONG.

\subsection{Interlocutoras}

Participaram desta pesquisa três adolescentes com idade entre 13 e 17 anos, em situação de exploração sexual, que frequentavam diariamente um turno da instituição. Duas já mantinham envolvimento com a exploração sexual, de acordo com informações dadas por membros da instituição, e a outra se envolveu durante a realização da pesquisa.

Interlocutora A: 17 anos, frequentava a Educação para Jovens e Adultos (EJA) no período noturno e participava da instituição havia três anos. Sua família era constituída por 11 irmãos, sua mãe e uma sobrinha.

Interlocutora B: 17 anos, frequentava a $8^{a}$ série e participava da instituição havia dois anos. Sua família era constituída por quatro irmãos, quatro primas e a sua avó paterna.

Interlocutora $C$ : 13 anos, frequentava a $6^{a}$ série e participava da instituição havia seis anos. Sua família era constituída por oito irmãos e sua mãe.

\subsection{Instrumentos}

Para a realização da pesquisa, foram utilizadas inicialmente a observação e atividades em grupo com materiais lúdicos. A observação foi realizada nos espaços de convivência das adolescentes na instituição. As atividades lúdicas foram desempenhadas para criar e, ou, fortalecer o vínculo pesquisadora-participante.

Depois foi realizada entrevista semiestruturada, que conteve questóes sobre aspectos biossociodemográficos, escola, lazer, corpo, gênero, família, infância e adolescência, atividades da exploração sexual, percepção sobre si e sobre os 
outros, afetividade, redes de apoio e projeto de vida. Em todas as etapas, foi confeccionado o diário de campo, a fim de relatar as observaçôes e impressões da pesquisadora sobre a realidade estudada. As perguntas contidas no roteiro semiestruturado foram reconstruídas e adaptadas à realidade de cada participante, tornando os termos adequados ao contexto em que estava inserida.

\subsection{Procedimento}

Para a realização da inserção ecológica com as adolescentes, foram feitas:

a) a aproximação da realidade da exploração sexual em Porto Alegre-RS, por meio da inserção em espaços políticos de discussão do tema na instância municipal e estadual;

b) a inserção no contexto institucional;

c) a inserção nas atividades institucionais com as adolescentes;

d) atividades lúdicas em grupo; e

e) as entrevistas individuais.

Para a primeira etapa, a pesquisadora visitou as instituições pertencentes à rede de atendimento a crianças e adolescentes vítimas de violência sexual e participou dos encontros estaduais e municipais sobre o tema. Para a segunda, foi escolhida uma instituição que atendesse diariamente adolescentes em atividades socioeducativas, possibilitando um acompanhamento continuado por meio da inserção ecológica. $\mathrm{Na}$ terceira, a pesquisadora participou com as adolescentes das atividades institucionais durante um mês e meio. Na quarta, foram feitos oito encontros semanais temáticos, com duração de aproximadamente duas horas. Na última etapa, foram realizados três encontros com cada participante, com duração de aproximadamente duas horas.

\subsection{Procedimento para análise do material produzido}

Os dados obtidos foram submetidos à análise de conteúdo, de acordo com o método de Bardin (1979). A partir da organização dos dados, foi realizada a leitura repetida e atenta de seu conteúdo e discussão dos dados, sendo levantados os temas abordados. Esse processo seguiu as fases de pré-análise, exploração dos materiais produzidos nas entrevistas e, em seguida, o tratamento dos dados, a inferência e a interpretação. A partir daí, foram produzidas categorias e subcategorias temáticas e analisadas qualitativamente, destacando diferenças e semelhanças entre os grupos. 


\section{DISCUSSÃO DOS RESULTADOS}

\section{1 “Daí eles ficam loucos com nós!": o corpo feminino como instrumento de poder sexual}

A descoberta do corpo como uma manifestação da identidade do ser humano tem sido apontada como uma das características mais incentivadas pela mídia na população adolescente (Figueira, 2004). No corpo, concretizar-se-ia sua identidade, sua visibilidade, tornando-se, assim, um projeto pessoal, um "corpoprojeto", como apontam Meyer e Soares (2008) e Couto (2009), sendo possível alterar, modificar com base nas lógicas que buscam na aparência a demonstração não somente de saúde, mas atrelada a ela, a da beleza, que na sociedade atual é entendida como um corpo magro, jovem, "turbinado". Segundo Goldenberg (2011), em nossa sociedade, o corpo almejado e produtor de desejo é um "corpomoeda", que, ao mesmo tempo, é produto de compra e venda, um corpo investido de uma economia da sexualidade, gerando nas mulheres o desejo de cuidar de seu corpo. Para as adolescentes estudadas, além da questão estética, o elemento sedutor aparece como mais um atributo de seu corpo. Nesse processo, ao se colocarem como objeto de desejo e prazer, vão constituindo sua feminilidade a partir do poder exercido pelo seu corpo jovem diante do masculino. Uma das interlocutoras, ao relatar a reação que provoca quando dança músicas de funk nos bailes que frequentava, demonstra o seu entusiasmo: "Um descontrole total, tá louco [...] Eles ficam loucos [...] Daí eles ficam louco com nós. Eu faço uns negócios para eles, né, e eles quase vão a loucura com nós" (Participante A, 17 anos).

A vinculação do elemento erótico à imagem das mulheres tem sido constantemente reiterada nas grandes mídias, como filmes, literatura, na publicidade e programas de tevê, na qual a sedução feminina seria o elementochave para que ocorra a manifestação de desejo e práticas sexuais na relação entre homens e mulheres (Câmara, 2007). Para a autora, há uma forte demarcação nas publicidades voltada para homens, de uma imagem masculina, heteronormativa, como um voyeur erótico que tem a sua estimulação sexual pela observação do corpo feminino. Esse olhar impõe ao corpo feminino a necessidade de que ele o satisfaça, como se fosse esse o seu objetivo último. De alguma forma, as adolescentes estudadas, ao darem-se conta dessa realidade, reconhecem o investimento oferecido ao seu corpo jovem e buscam, a partir disso, fazerem uso desse lugar de visibilidade. A participante A fazia parte de um grupo de meninas, conhecido popularmente em festas funk como "bondes", que ensaiava e se apresentava nessas festas não para ganhar dinheiro, mas exatamente para estar em um lugar de destaque, para serem mais vistas. A constituição da feminilidade 
por esse olhar masculino pode atribuir às mulheres a ideia de que o seu corpo e sexualidade estão à mercê do desejo masculino, cabendo, assim, o esforço para que esse olhar permaneça e se perpetue. Goldenberg (2011), ao discutir o conceito de "dominação masculina" em Pierre Bourdieu, fala da dependência simbólica existente no processo de constituição do corpo feminino que surge a partir desse olhar do outro, o qual, em nossa sociedade, o configura como algo disponível, aberto e sedutor. Dessa forma, esse olhar masculino é algo que deve ser manifestado abertamente, de uma maneira que deixe clara a existência do desejo sexual despertado por esse corpo como garantia de uma masculinidade heterossexual. Tais concepções acabam por legitimar que o corpo feminino assuma essa função de satisfação masculina mesmo quando não há a permissão da mulher para que isso ocorra, como mostra o relato da participante B:

Mas eu acho que os guris também são muito [...] Só, só olham para corpo das gurias se a guria é bonita ou feia, o importante é que tenham corpo, porque eles querem é passar a mão. [...] Um guri me agarrava à força na rua, nós ficamos sentadas na pedra, e um guri veio para cima de mim, e a minha mãe pensou que fui eu que deixei o guri me agarrar (Participante B, 17 anos).

O exercício da função masculina nos comportamentos afetivo-sexuais em nossa sociedade muitas vezes é manifestado de forma explícita e pública, seja por meio de olhares, sorrisos e uso de palavras, como forma de garantir a masculinidade tanto para si como para os outros, mesmo quando feita de forma mecânica (Heilborn, 1999). Muitos homens, para se sentirem "machos", assediam o corpo feminino e, em muitos casos, tal assédio pode se tornar violento quando não é levado em consideração o desejo ou a aceitação feminina. A representação da sexualidade masculina heterossexual costuma ser caracterizada como "descontrolada", em permanente estado de vigília ao seu desejo sexual, o que, no contexto da violência sexual contra a mulher, costuma ser usada como justificativa para o comportamento agressor masculino (Felipe, 2006). A própria participante A reconhece essa sexualidade "descontrolada", ao descrever as reaçôes dos homens à sua volta quando cita "Eles vão a loucura com nós" (sic). Tais concepções podem fragilizar as mulheres nas suas relações afetivo-sexuais, pois contribuem para as dificuldades na expressão de sua vontade quando esta contraria o desejo masculino. Em alguns relatos de experiências em atendimento com adolescentes em situação de exploração sexual, o corpo feminino apresentou-se como alvo de agressões sexuais por homens, sejam eles da família ou desconhecidos, que se autorizaram a tocar o corpo feminino em busca do seu prazer, mesmo sem o consentimento das adolescentes (Trindade, 2005; Verardo, Reis, \& Vieira, 1999). Assim, as adolescentes estudadas retrataram a ambiguidade de vivenciar um corpo feminino que, por um lado, propicia-lhe poder pela valorização social 
que tem, mas, por outro, pode vulnerabilizá-la quando não são respeitados os seus direitos.

\section{2 "O cara deu 200 pila para tirar a virgindade dela": a virgindade e o seu papel nas relações de gênero}

O valor pago por um corpo não iniciado sexualmente no mercado do sexo e o reconhecimento da virgindade como garantia de uma sexualidade feminina responsável fez com que essa questão neste estudo assumisse um lugar de destaque tanto na relação das meninas com suas mães e quanto com os clientes. Mesmo com as mudanças ocorridas pela luta dos movimentos feministas pelo reconhecimento dos direitos das mulheres, entre eles o de ter o domínio sobre o seu corpo, foi possível perceber, nos casos pesquisados, que sexualidade feminina ainda é alvo de controle social. Nos relatos das três interlocutoras, a virgindade surgiu como um elemento importante para definir a sua sexualidade perante a sociedade, principalmente em relação a suas mães. Como mostram os relatos das interlocutoras A e B, a perda da virgindade ou a manutenção dela geraram impactos na família, principalmente em suas mães, como mostra o relato a seguir: "E a minha mãe não sabia que eu não era mais virgem. Esse guri aqui ligou para minha casa: 'Dona S., tu sabe que a tua filha não é mais virgem mais'. 'Não? Capaz.' A minha mãe me deu porrada. Bateu em mim quando eu perdi a virgindade" (Interlocutora A, 17 anos).

Já para a interlocutora B, sua virgindade era utilizada como um elemento diferenciador para sua história de vida em relação à de sua mãe, que "perdeu a virgindade aos 15 anos" (sic). Além desse aspecto, a virgindade era uma "prova" de que ela não fazia sexo e, com isso, não corria o risco de engravidar. Tal fato contribuía para que ela se reconhecesse como uma adolescente responsável:

Eu acho que eu sou mais responsável, eu acho. É isso, eu acho. Porque muitas meninas na minha idade já têm filhos, né, e eu não. Eu podia ter, né, porque a minha mãe não se importava comigo, nunca se importou e, na rua, se eu quisesse, eu já tinha filho, né, se eu quisesse, né (Interlocutora B, 17 anos).

Com a participante $\mathrm{C}$, sua condição de ser virgem foi abordada em várias situações nas quais a pesquisadora e participante conviveram na pesquisa. Em uma das etapas do estudo, a participante fez questão de mostrar para a pesquisadora a sua resposta em um questionário feita pelas adolescentes da instituição, no qual relatava essa situação.

Segundo Santos (2004), a sexualidade feminina está inserida numa construção social e cultural de gênero que estabelece diferenças entre homens e mulheres num 
processo de desigualdade em que há a dominação masculina sobre a feminina. A virgindade, ao longo da história, assumiu um lugar determinante para definir o lugar social da mulher, o que não ocorria com os homens, que tinham, por outro lado, o incentivo para que o sexo ocorresse independentemente de estar vinculado ao casamento. Segundo Roberts (1992), o comportamento sexual da mulher considerada "honesta" estava voltado especificamente para o casamento, com a função primordial de procriação. A virgindade, assim, para as mulheres solteiras, representava a garantia dessa "honestidade" perante a sociedade. Para adolescentes em situação de risco e vulnerabilidade social, deixar de ser virgem pode representar a perda da possibilidade de conseguir um bom casamento já que deixariam de ser uma mulher "de bem" (Verardo, Reis, \& Vieira, 1999, p. 55). A perda da virgindade pode desvalorizar a adolescente perante o seu grupo e, com isso, vulnerabilizá-la socialmente (Hazeu \& Fonseca, 1998).

Num estudo realizado com 920 adolescentes do ensino fundamental, numa escola da cidade de São Paulo, sobre questões da sexualidade, na questão sobre a importância da virgindade, a resposta foi afirmativa em $66 \%$ dos meninos e 91\% das meninas (Bretas, Ohana, Jardim, Aguiar Junior, \& Oliveira, 2011). Tal fato aponta que a virgindade ainda é reconhecida como um atributo da sexualidade feminina e, como tal, é cobrado não somente pelo discurso masculino como também nas figuras de autoridade feminina na família, como a mãe. Em um estudo realizado com mães vítimas de violência doméstica, a exigência da virgindade apareceu como uma forma de as suas filhas garantirem um casamento melhor do que o delas (Serpa, 2010a). Em outro estudo realizado sobre mulheres advindas das classes socioeconômicas desfavorecidas no início da urbanização no Brasil, a virgindade seria a garantia para as mães de que as suas filhas não seriam mães solteiras e, com isso, conseguiriam um bom casamento (Fonseca, 2006; Soihet, 2006). Para Soihet (2006), a honra da mulher estaria vinculada à figura masculina, seja pela sua ausência, com a virgindade, seja pela sua presença, com o casamento.

No mercado do sexo, a virgindade aparece como uma moeda de troca valorosa, na qual é possível negociar por um preço maior do que o programa comum, como mostra a seguinte fala: "Quando ela perdeu, né. O cara deu 200 contos para ela (sua irmã), foi o que ela falou para mim, né. O cara deu 200 pila, deu 200 contos para ela, para tirar a virgindade dela da frente, daí ela foi, né" (Participante A, 17 anos).

Nas reportagens apresentadas por Dimenstein (1992), a virgindade aparece como um elemento valorizado na exploração sexual. Segundo tais reportagens, em algumas cidades do norte do Brasil, as crianças e adolescentes virgens são anunciadas publicamente e depois leiloadas em boates. Os clientes que buscam a 
prática sexual com crianças e adolescentes são estimulados pelo alto valor atribuído socialmente às práticas sexuais associadas à juventude. O forte apelo das grandes mídias para a associação entre infantilização e erotização das imagens femininas e o espaço que esse corpo ocupa no mercado do sexo faz com que a virgindade, em alguns casos, seja vista como algo de grande valia para aqueles que acessam esse mercado. A grande repercussão do caso da jovem catarinense de 20 anos que leiloou a sua virgindade na internet, como parte de um documentário, aponta a relevância dessa questão. Numa das entrevistas dadas a um programa de televisão brasileira, a jovem é descrita inicialmente com "jeito de menina, sensual". Mais recentemente, a novela Verdades Secretas, transmitida por uma das emissoras brasileiras, tinha como um dos fios condutores de sua trama o forte desejo sexual de um homem adulto por uma adolescente. Tal personagem, reiterada vezes, mostrava o forte atrativo sexual despertado pela adolescente, por meio do seu "jeito menina" de ser, percebida como inexperiente, ingênua, desamparada tanto afetivamente pela figura paterna como no aspecto financeiro. Essa associação com a imagem de "pureza" e "inocência" trazida pela ideia desse "jeito menina" potencializa um investimento erótico por parte do universo masculino adulto nos corpos infantojuvenis ao vê-los como corpo um objeto de dominação e a prática sexual como um exercício de poder.

Além desses aspectos, a virgindade foi citada pala participante A como um critério para delimitar a sua entrada na exploração sexual, já que, enquanto virgem, não poderia ser identificada como uma adolescente envolvida na exploração sexual, mesmo estando envolvida com essa prática: "Eu não fazia nada, né. Ela fazia, né, ela não era mais virgem, né. Eu ficava esperando ela no centro, né, na esquina ali" (Participante A, 17 anos).

$\mathrm{Na}$ separação estabelecida pela participante A entre a fase mulher "moça" e a mulher na situação de exploração sexual, observa-se que a perda da virgindade aparece como um fator que justifica a entrada ou permanência da adolescente na prática da exploração sexual. Em um relato de uma adolescente, mesmo pegando caronas com caminhoneiros para realizar programas, afirmava que não estava em situação de exploração sexual por ainda ser virgem (Verardo, Reis, \& Vieira, 1999). Já de acordo com os relatos mostrados em Trindade (2005), a avó de uma das adolescentes, ao saber da perda da virgindade de sua neta, passou a incentivála para a exploração sexual como uma maneira de trazer dinheiro para a casa. Em um trabalho realizado em Teresina, Piauí, a expressão "prostitui-se" foi utilizada para adolescentes que experimentavam a sua primeira relação sexual antes do casamento (Serpa, 2010a). Quando isso ocorria ou quando havia dúvidas sobre esse fato, as mães das adolescentes cogitavam a possibilidade de submetê-las a um exame de virgindade. Dessa forma, para as interlocutoras, a virgindade 
apresentou-se como um dos elementos definidores para o seu papel social como mulher, assim como instrumento de controle de sua sexualidade.

\section{CONSIDERAÇÕES FINAIS}

Este estudo teve como objetivo analisar as questóes de corpo e gênero vivenciadas por adolescentes do sexo feminino envolvidas com a exploração sexual nas suas experiências cotidianas. Nessas experiências, a sensualidade apareceu como um forte atributo dos seus corpos para o exercício da sua feminilidade, principalmente nas relações com o masculino. A percepção dos efeitos provocados com a sua presença perante os olhares masculinos descreve a força exercida por esse corpo, capaz de provocar "loucura" (sic) nos homens. Nesse jogo erótico de ser vista e admirada, as adolescentes vivenciam uma sensação de prazer e valorização de sua feminilidade. Com isso, aprendem que, na relação com o masculino, a sua feminilidade também é constituída por "esse olhar", investido de eroticidade, que, por um lado, reveste o corpo feminino de poder, por outro, legitima uma sexualidade masculina heterossexual passível de descontrole, e por isso capaz de cometer atos irracionais diante desse corpo, justificando, com isso, muitas das violências sexuais sofridas pelas mulheres. Se, por um lado, a erotização do corpo feminino é capaz de potencializá-lo, por outro, coloca-o em condição de vulnerabilidade por responsabilizá-lo por qualquer reação que possa provocar nos homens. Tal fato pode ser visto em casos descritos sobre a violência sexual nos quais os questionamentos se voltam para como esse corpo feminino se encontrava, como se, ao estar exposto, estivesse passível dessa violência. Dessa forma, as adolescentes vivenciam a dubiedade sobre o seu corpo ao estarem diante de uma lógica, que, ao mesmo tempo em que as investem de poder e prazer, pode a destituir de autonomia e de direitos.

A virgindade apareceu como um elemento importante na definição da sexualidade das interlocutoras perante a sociedade. Para as mães das adolescentes estudadas, a virgindade é a garantia da manutenção dos "bons costumes" femininos. Tal exigência, muitas vezes estabelecida de forma agressiva, manifesta uma lógica moralizadora da sexualidade feminina. Nesses casos, as adolescentes encontram dificuldade em estabelecer, no seu espaço familiar, relações que rompam com as normas estabelecidas por uma cultura patriarcal. Num contexto mais amplo, como no mercado do sexo, a virgindade das adolescentes apareceu como uma forte moeda de troca, sendo assim um elemento significativo para a aproximação delas à exploração sexual.

No caso das adolescentes estudadas, fez-se necessária a análise sobre o seu corpo e o papel que ele assume na prática da exploração sexual. Por se tratar de 
uma atividade comercial, as adolescentes estabelecem trocas nas quais as práticas sexuais são vendidas como mercadoria. No mercado do sexo, a adolescente percebe no seu corpo uma grande possibilidade de ser bem remunerada, diferente de outras atividades que podem desempenhar no contexto em que estão inseridas (Farinha \& Bruns, 2006). Para as autoras, o mercado do sexo não demanda das adolescentes nenhum pré-requisito profissional para o seu exercício, a não ser o fato de serem jovens e sem experiência. E nos casos estudados, a virgindade mostrou-se ser um "produto valioso".

Assim, nas práticas de enfrentamento da exploração sexual, a análise do corpo, gênero e sexualidade torna-se uma ferramenta privilegiada para avaliar as concepções sobre a mulher, inter-relacionadas com os aspectos sociais, políticos, históricos e psicológicos que contribuem tanto para o aparecimento como para a manutenção da violência sexual. Diante disso, observa-se a importância de estratégias que permitam as adolescentes refletirem sobre como as questões acima citadas influenciam as concepções que elas constroem sobre a sua feminilidade e como isso contribui para a sua vulnerabilidade social. Dessa forma, espera-se que as adolescentes estabeleçam comportamentos mais autônomos na manifestação da sua sexualidade, pautados em uma lógica que as considere como sujeitos de direitos. 


\section{REFERÊNCIAS}

Andrade, S. S. (2013). Mídia impressa e dos corpos educação femininos. In G. L. Louro, J. Felipe \& S. V. Goellner (Eds.), Corpo, gênero e sexualidade: um debate contemporâneo na educação (9a ed.). (pp. 108-123). Petrópolis: Vozes.

Bardin, L. (1979). Análise de conteúdo. L. A. A. Pinheiro( Trad.), São Paulo: Edições 70; Livraria Martins Fones

Bretas, J. R., Ohara, C. V., Jardim, D. P., Aguiar Junior, W., \& Oliveira, L. R. (2011). Aspectos da sexualidade na adolescência. Ciência \& Saúde Coletiva, 16(7), 3221-3228.

Câmara, A. P. (2007). Gênero e sexualidade na revista Sexy: um roteiro para a masculinidade heterossexual (Dissertação de Mestrado). Universidade Federal do Rio Grande do Sul, Programa de Pós-Graduação em Educação, Porto Alegre.

Couto, E. S. (2009). Uma estética para os corpos mutantes. In E. S. Couto, \& S. V. Goellner (Orgs.), Corpos mutantes: ensaios sobre novas (d) eficiências corporais. (2a ed.). (pp. 43-56). Porto Alegre: Editora da UFRGS.

Dimenstein, G. (1992). Meninas da noite. (8a ed.). São Paulo: Átila.

Ennew, J. (2008). Explotation of children in prostitution. In Anais, 3 Congresso Mundial de Enfrentamento da Exploração Sexual de Crianças e Adolescentes, Rio de Janeiro.

Eschiletti, P. L., Paula, C. M. C. P., Moura, A., Poletto, M., \& Koller, S. (2008). Revisando a inserção ecológica: uma proposta de sistematização. Psicologia: Reflexão e Crítica, 21(1), 160-169.

Faleiros, V. P. (2004). O fetiche da mercadoria na exploração sexual. In R. M. C. Libório \& S. M. G. Sousa (Orgs.), Exploração sexual de crianças e adolescentes no Brasil: reflexôes teóricas, relatos de pesquisa e intervençôes psicossociais. (pp. 5172). São Paulo: Casa do Psicólogo; Goiânia: Universidade Católica de Goiás.

Farinha, M. G. \& Bruns, M. A. T. (2006). Adolescentes profissionais do sexo. Campinas: Átomo.

Felipe, J. (2006, janeiro,junho). Afinal, quem é mesmo pedófilo? Cadernos Pagu, 26, 201-223. 
Felipe. J. (2013). Erotização dos corpos infantis. In G. L. Louro, J. Felipe \& S. V. Goellner (Eds.), Corpo, gênero e sexualidade: um debate contemporâneo na educação (9a ed.). (pp. 53-65). Petrópolis: Vozes.

Figueira, M. L. M. (2004). A revista Capricho e a produção de corpos adolescentes femininos. In G. L. Louro, J. Felipe, \& S. V. Goellner (Eds.), Corpo, gênero e sexualidade: um debate contemporâneo na educação (9a ed.). (pp. 125-135). Petrópolis: Vozes.

Fonseca, C. (2006). Ser mulher, mãe e pobre. In M. D. Priore (Ed.), História das mulheres no Brasil (pp. 510-554). São Paulo: Contexto.

Goellner, S. V. (2013). A produção cultural do corpo. In G. L. Louro, J. Felipe, \& S. V. Goellner (Eds.), Corpo, gênero e sexualidade: um debate contemporâneo na educação (9a ed.). (pp. 28-40). Petrópolis: Vozes.

Goldenberg, M. (2011). Corpo, envelhecimento e felicidade: diferenças de gênero na cultura brasileira. Contemporânea, 18(12),78-85. Recuperado a partir de http://www.contemporanea.uerj.br/pdf/ed_18/contemporanea_ n18_06_Mirian_Goldenberg.pdf

Guizzo, B. S. \& Felipe, J. (2003). Erotização dos corpos infantis na sociedade de consumo. Revista Pro-Posiçôes, 14(3), 119-132.

Hazeu, M. \& Fonseca, S. (1998). Exploração e violência sexual contra crianças e adolescentes no Pará. In M. F. P Leal \& M. A. César (Eds.), Indicadores de violência intrafamiliar e exploração sexual comercial de crianças e adolescentes (pp. 57-67). Brasília: Cecria.

Heilborn, M. L. (1999). Corpos na cidade: sedução e sexualidade. In G. Velho (Ed.), Antropologia urbana: cultura e sociedade no Brasil e em Portugal. (pp. 98108). Rio de Janeiro: Jorge Zahar.

Landini, T. S. (2011). Análise qualitativa das entrevistas realizadas na pesquisa sobre exploração sexual e desaparecimento de crianças e adolescentes da baixada santista. In J. F. Gilka, F. Gracia, \& T. S. Landini, Caminho de volta desaparecimento e exploração sexual de crianças e adolescentes: relatos de pesquisa. (pp. 59-64). São Paulo: edição do autor.

Leal, M. L. P. (1999). A exploração sexual comercial de meninos, meninas e adolescentes na América Latina e Caribe: relatório final, Brasil. Brasília: Cecria. 
Libório, R. M. C. (2004). Exploração sexual comercial infantojuvenil: categorias explicativas e políticas de enfrentamento. In R. M. Libório \& S. M. G Sousa (Orgs.), Exploração sexual de crianças e adolescentes no Brasil: reflexões teóricas, relatos de pesquisa e intervenções psicossociais. (pp. 19-50). São Paulo: Casa do Psicólogo; Goiânia: Universidade Católica de Goiás.

Louro, G. P. (2013). Gênero, sexualidade e educação: uma perspectiva pósestruturalista (9a ed.). Petrópolis: Vozes.

Mello, L. C. A. (2010). Exploração sexual de crianças e adolescentes: o estado da arte nas produçôes acadêmicas em Psicologia. (Dissertação de Mestrado). Universidade Federal do Rio Grande do Norte, Programa de Pós-Graduação em Psicologia, Natal.

Meyer, D. E. \& Soares, R. (2008). Corpo, gênero e sexualidade nas práticas escolares: um início de reflexão. In D. Meyer \& D. Soares (Orgs.), Corpo, gênero e sexualidade. (pp. 5-16). Porto Alegre: Mediação.

Moraes, A. F. (1998). Prostituição, trocas e convites sexuais na adolescência feminina pobre. In C. Bruschini \& B. Hollanda. (Orgs.), Horizontes plurais: novos estudos de gênero no Brasil. (pp. 17-47). São Paulo: Fundação Carlos Chagas e Editora 34.

Moraes, A. F. (2011). Corpos normalizados, corpos degradados: os direitos humanos e as classificaçōes sobre prostituição de adultas e jovens. In Anais do 11 Congresso Luso-Afro-Brasileiro de Ciências Sociais. (pp. 1-22), Salvador.

Roberts, N. (1992). As prostitutas na história. Rio de Janeiro: Record; Rosa dos Tempos.

Santos, B. R. dos (2004). Contribuições para um balanço das campanhas de combate ao abuso e exploração sexual de crianças e adolescente no Brasil. In R. M. Libório \& S. M. G. Sousa (Orgs.), Exploração sexual de crianças e adolescentes no Brasil: reflexóes teóricas, relatos de pesquisa e intervençóes psicossociais. (pp. 99148). São Paulo: Casa do Psicólogo; Goiânia: Universidade Católica de Goiás.

Serpa, M. G. (2009). Exploração sexual e prostituição: um estudo de fatores de risco e proteção com mulheres adultas e adolescentes. (Dissertação de Mestrado). Universidade Federal do Rio Grande do Sul, Programa de Pós-Graduação em Psicologia, Porto Alegre.

Serpa, M. G. (2010a). Perspectivas sobre papéis de gênero masculino e feminino: um relato de experiência com mães de meninas vitimizadas. Psicologia \& Sociedade, 22(1), 14-22. 
Serpa, M. G. (2010b). Primeiras experiências de exploração sexual: um estudo sobre o processo de aproximação de adolescentes a essa realidade. Psico, Porto Alegre, 41(1), 32-39.

Soihet, R. (2006). Mulheres pobres e violência no Brasil. In M. D. Priore (Ed.), História das mulheres no Brasil. (pp. 223-277). São Paulo: Contexto.

Trindade, E. (2005). As meninas da esquina. São Paulo: Record.

Vega, L. B. S. (2011). Exploração sexual de crianças e adolescentes e as redes de proteção: um estudo socioambiental na cidade do Rio Grande. (Dissertação de Mestrado). Universidade Federal de Rio Grande, Programa de Pós-Graduação em Educação Ambiental, Rio Grande.

Verardo, M. T., Reis, M. S. F., \& Vieira, R. M. (1999). Meninas do porto: mitos e realidade da prostituição infantojuvenil. São Paulo: O Nome da Rosa.

Yin, R. K. (2001). Estudo de caso: planejamento e métodos. (2a ed.). Porto Alegre: Bookman. 